\title{
O Professor no Espelho: conscientização e mudança pela auto-observação
}

\author{
Andréa Machado de Almeida Mattos \\ Universidade Federal de Minas Gerais
}

"Not to examine one's practice is irresponsible; to regard teaching as an experiment and to monitor one's performance is a responsible professional act."

(Ruddock, 1984 apud Williams \& Burden, 1997:55)

This paper reports on a study which investigated a pre-service English teacher and her own perceptions about her classroom. The research design aimed at fostering the informant's critical reflection about her classroom performance in order to promote her professional development. An interpretivist and emic vision was adopted, during both the data collection phase and the data analysis phase. The results showed evidence of change in the participant's performance, suggesting that the data collection methodology favored the informant's critical reflection, fostering her professional development. Based on the research findings, Wallace's (1991) model for FL teacher education was modified. The results of this study bring implications to the field of FL teacher education and to the relationship between the researcher and the participant-teacher.

Este trabalho relata uma pesquisa que investigou uma professora de inglês em formação e suas percepções sobre sua sala de aula. A pesquisa objetivou fomentar a reflexão crítica da informante sobre sua atuação dentro da sala de aula de forma a promover seu desenvolvimento profissional. Foi adotada uma visão interpretativista e êmica tanto durante a fase de coleta dos dados quanto na fase de análise. Os resultados relevaram evidencias de mudanças no comportamento da informante ,sugerindo que a metodologia utilizada para a coleta dos dados favoreceu a reflexão crítica da informante, promovendo seu desenvolvimento profissional. Com base nos 
resultados da pesquisa, o modelo para formação do professor de LE de Wallace (1991) foi modificado. Os resultados deste estudo trazem implicações para o campo da formação do professor de LE e para a relação existente entre pesquisador e professor-pesquisa.

\section{Introdução}

Embora seja crescente o número de pesquisadores que se interessam pelo professor de língua estrangeira (LE), o campo da formação do professor de LE ainda carece de pesquisas cujos resultados possam realimentar o processo de formação de professores nos cursos de licenciatura em todo o país. A fim de contribuir para uma melhor compreensão do processo de ensinar uma língua estrangeira, este trabalho relata uma pesquisa que investigou uma professora de inglês em formação e suas percepções sobre sua sala de aula a partir de seu próprio ponto de vista. ${ }^{1}$ A pesquisa procurou fomentar a reflexão crítica da informante sobre sua atuação dentro da sala de aula, de forma a promover seu desenvolvimento profissional, adotando uma perspectiva interpretativista e êmica, tanto para a coleta quanto para a análise dos dados. O objetivo principal deste trabalho será, assim, discutir as mudanças evidenciadas no comportamento da professora em relação à sua prática a partir da auto-observação e a avaliação dessa professora sobre sua participação na pesquisa. Como a pesquisa intencionou promover a reflexão crítica da professora participante, primeiramente será feita uma breve retrospectiva do uso da reflexão na formação do professor de LE, apresentando-se o modelo reflexivo de Wallace (1991), que serviu de ponto de partida para a análise dos dados. Em seguida serão discutidos o papel da supervisão na formação do professor de LE e a relação que se estabelece entre o professor pesquisado e o pesquisador, já que a atitude e a postura do supervisor ou pesquisador influenciam os rumos do desenvolvimento profissional do professor em formação. A metodologia utilizada na pesquisa também será relatada passo a passo e os dados obtidos serão apresentados e discutidos à luz da teoria resenhada. Por fim, será proposta uma ampliação do modelo reflexivo de Wallace (1991) com base nos resultados deste trabalho, os quais trazem implicações para o campo da formação do professor de LE e para a relação existente entre pesquisador e professor-pesquisado.

\section{A Reflexão na Formação do Professor de LE}

A preocupação com a formação do professor de língua estrangeira, no Brasil, se intensificou a partir do início dos anos 90. Dentre os pesquisadores que se interessam por essa área podemos citar Almeida Filho (1993), Gimenez (1994) e Moita Lopes (1996). Mais recentemente, esse novo campo tem sido chamado de formação continuada do professor de LE (Almeida Filho, 1997; Baghin \& Alvarenga, 1997), e pretende incluir, segundo esses autores, "não apenas os cursos de pós-graduação e reciclagem realizados por professores em serviço, mas também as atividades em que o professor se engaja solitária e independentemente, com o objetivo de refletir sobre o próprio trabalho sem o concurso de outrem" (Almeida Filho, 1997:31). 
Segundo Moita Lopes (1996), os professores de LE no Brasil recebem uma formação teórica dogmática, isto é, "são treinados a partir de certos modismos sobre como ensinar línguas" (p.180). Para que essa visão dogmática da formação do professor de línguas seja superada é preciso que "o professor ainda em formação envolva-se na reflexão crítica sobre seu próprio trabalho" (ibid, p.184).

Bartlett (1990) já sugeria que é possível melhorar a qualidade do ensino de professores em formação através da reflexão. Para ele, refletir é mais do que 'pensar' e envolve tanto as atividades rotineiras do professor ligadas à sala de aula quanto aquelas ligadas ao contexto institucional em que o professor se insere. Segundo Bartlett (ibid, p. 204), Kemmis (1986:5) assim definiu a prática da reflexão:

"Reflexão não é apenas um processo psicológico individual. É uma estrutura social e política, historicamente construída e orientada para a ação, para que o indivíduo se localize na história de uma situação, participe de uma atividade social, e assuma posições sobre determinadas questões. (...) através da reflexão e da ação que ela informa, podemos transformar as relações sociais que caracterizam nosso trabalho e o contexto no qual ele se insere."

Ainda segundo Bartlett, para tornar-se crítico, o professor deve "transcender as tecnicalidades do ensino e pensar além da necessidade de melhorar suas técnicas instrucionais." Isso significa abandonar perguntas do tipo "como fazer?", que têm um valor limitado, e passar a fazer perguntas do tipo "o quê?" e "por quê?", as quais consideram as práticas rotineiras do professor "não como um fim em si mesmas mas como parte de objetivos educacionais mais amplos" (ibid, p. 205).

Vários autores têm utilizado a reflexão como instrumento para o desenvolvimento do professor de LE. Dentre eles, Richards \& Lockhart (1994) propõe uma abordagem reflexiva para uma melhor compreensão do processo de ensino e aprendizagem de LE, sugerindo que

"Professores e professores-aprendizes devem coletar dados sobre ensino, examinar suas atitudes, crenças, pressuposições e práticas de sala de aula, e usar as informações obtidas como uma base para a reflexão crítica sobre o ensino" (ibid, p.1).

Wallace (1991) discute três modelos de educação do professor. O primeiro, denominado "modelo craft", via a atividade do professor como uma arte que deveria ser ensinada aos novatos por um profissional experiente e detentor do saber da profissão - 0 mestre. Esse modelo, porém, é muito conservador, pois perpetua indefinidamente o "saber" do mestre. $\mathrm{O}$ modelo tem certo valor e não deve, segundo Wallace, ser completamente eliminado, pois professores-aprendizes com certeza têm muito para aprender com um profissional mais experiente. Além disso, um dos pontos fortes do modelo é justamente o alto valor atribuído ao "conhecimento experiencial", isto é, aquele advindo da experiência prática.

Um outro modelo, chamado de "modelo de ciência aplicada", se desenvolveu a partir das descobertas empíricas da ciência e professa que os problemas relacionados ao ensino "podem ser solucionados através da aplicação da ciência empírica aos objetivos desejados" (ibid, p. 8). Assim, os resultados da experimentação científica eram passados 
para os aprendizes por aqueles que são especialistas nas várias áreas do conhecimento, o que levou a uma separação entre aqueles que pensam a profissão e aqueles que a exercem (ibid). Ao criticar o modelo, Wallace lembra que "ensino de qualidade é uma atividade inquestionavelmente complexa, e não há garantia de que poderá ser totalmente previsível de forma lógica de acordo com princípios "científicos"” (ibid, p. 7). Apesar dos conhecidos problemas desse modelo, o autor acredita que esse ainda é o modelo mais praticado na maioria dos programas de treinamento de novos profissionais.

Insatisfeito com as limitações de ambos os modelos, Wallace propõe um terceiro, o "modelo reflexivo", que tenta unir os pontos positivos dos dois modelos anteriores, ou seja, a experiência e a base científica da profissão. Baseando-se nas idéias de Schön (1983), Wallace sugere que a educação do professor tem duas dimensões principais: o conhecimento recebido, na forma de saber científico, e o conhecimento experiencial, relativo à experiência profissional.

O conhecimento recebido se constitui de informações e teorias, normalmente relacionadas a algum tipo de pesquisa e que são amplamente encontradas como parte do programa de cursos de treinamento para professores (Wallace, 1991:12). Já o conhecimento experiencial está relacionado ao que Schön (1983) chamou de "conhecimento na ação"3 e se constitui no saber tácito que o professor adquire como conseqüência natural de uma prática competente da profissão. No modelo proposto, é crucial o papel da reflexão do professor como instrumento promotor do autodesenvolvimento. Segundo Wallace (1991:13), é a reflexão que permite aos professores o desenvolvimento consciente de "insights" sobre sua prática, transformando-os em "conhecimento na ação". Esses aspectos formam, então, a base do Modelo Reflexivo sugerido pelo autor como uma alternativa para se fugir dos modelos anteriores e promover o desenvolvimento da competência do professor.

O modelo, conforme representado na figura 1 a seguir, é dividido em três estágios: o estágio pré-treinamento, no qual o aprendiz se encontra antes de iniciar o processo de desenvolvimento profissional; o estágio de educação ou desenvolvimento profissional propriamente dito; e o objetivo, ou seja, a competência profissional almejada.

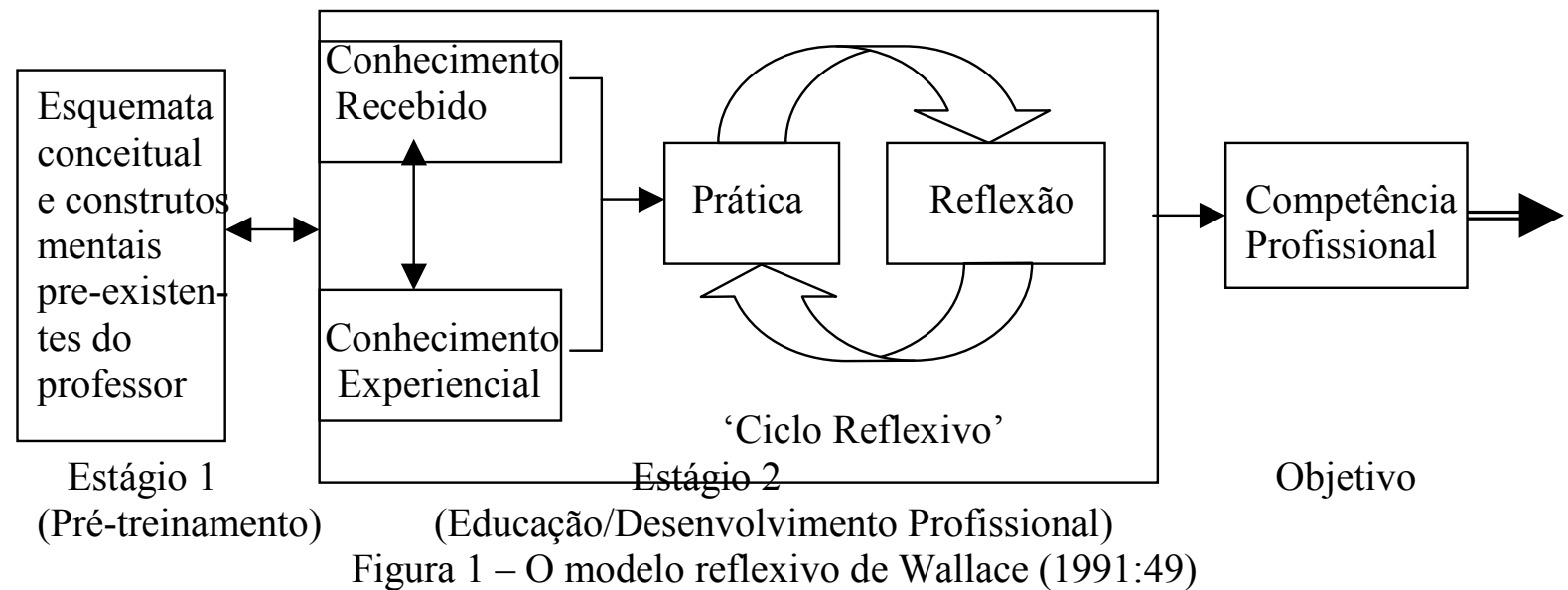

O estágio pré-treinamento corresponde, como se vê, àquilo que o aprendiz traz consigo para o processo de treinamento ou desenvolvimento ${ }^{4}$. $O$ estágio de desenvolvimento profissional inclui o conhecimento recebido, na forma de dados, fatos e 
teorias associados à profissão, e o conhecimento experiencial do aprendiz. Os dois tipos de conhecimento, no entanto, estão ligados por uma seta bidirecional, o que simboliza uma relação recíproca entre os dois. Wallace estabelece como corolário que "o conhecimento recebido deve tanto informar diretamente o conhecimento experiencial quanto ser informado por ele" (p. 52). Contudo, o modelo dá maior ênfase ao conhecimento experiencial e ao papel da reflexão do professor sobre esse conhecimento como o caminho para se chegar à competência profissional. Wallace salienta que "desenvolvimento implica em mudança, e mudança frutífera é extremamente difícil sem reflexão" (p. 54). Ou seja, na visão do autor, para chegar à almejada competência profissional, o professor necessita de refletir sobre a sua própria prática, relacionando novas informações e idéias ao seu conhecimento anterior e às suas preocupações profissionais. Dessa forma, o professor em formação será capaz de avaliar sua prática profissional e realizar mudanças em seu comportamento, num processo contínuo de desenvolvimento. Além disso, Wallace lembra que não basta que a reflexão aconteça, mas ela deve também ser de boa qualidade. Um dos objetivos principais do modelo proposto é, então, melhorar a qualidade da reflexão para se chegar a um maior desenvolvimento profissional. O modelo reflexivo argumenta também que o aprendiz deve refletir sobre o conhecimento recebido à luz da experiência obtida na sala de aula, de forma que essa experiência possa também realimentar o conhecimento recebido. O foco principal do modelo é, portanto, de um lado a prática e de outro a reflexão.

O último estágio do modelo é a competência profissional enquanto objetivo final. Wallace descreve esta competência profissional como "um alvo em movimento ou um horizonte, em cuja direção os profissionais viajam durante toda sua vida profissional, mas que nunca é finalmente alcançado" (p. 58). Por isso, na representação gráfica do modelo (figura 1), há uma seta que parte do quadro final, indicando que a competência profissional não é um ponto de chegada mas sim um ponto de partida.

O modelo proposto por Wallace é, sem dúvida, um avanço em relação a modelos anteriores de treinamento de professores. Além de levar em consideração as fontes de aprendizagem do professor, o modelo coloca a prática de sala de aula como um prérequisito central para se chegar à competência profissional. $\mathrm{O}$ modelo também prioriza $\mathrm{O}$ papel da reflexão no processo de aprendizagem do professor e ressalta que as atividades diárias e a prática da reflexão devem formar um ciclo que leva à competência profissional. Esta, porém, não pode ser vista como um objetivo final, pois o professor está sempre em processo de mudança assim como sua competência profissional.

\section{O Papel da Supervisão na Formação do Professor de LE}

Como já foi dito, verifica-se no Brasil um crescente interesse pela melhoria da formação do professor de inglês como LE. Para isso, é fundamental pesquisar o que os professores sabem sobre a prática de ensinar uma LE e como eles aprendem essa prática, tendo como foco o ponto de vista do próprio professor.

Muitos pesquisadores defendem que a interação com a figura de um supervisor exerce papel importante na formação do professor-aprendiz. Essa questão é abordada por vários autores compilados em Richards \& Nunan (1990), que discutem principalmente os problemas e benefícios que essa interação pode trazer para o professor em formação. 
Freeman (1990), por exemplo, examina a interação entre o professor em formação e seu supervisor e defende que "o professor-aprendiz pode ser ajudado a ensinar de forma mais eficaz através do input e das percepções do professor-educador" (p.105). Assim, o autor discute três diferentes opções de supervisão que permitem a interação entre $o$ professor-aprendiz e seu supervisor. A primeira é a opção diretiva, na qual o supervisor tece comentários sobre a atuação do professor-aprendiz, fazendo propostas concretas de mudanças. A segunda é a opção de alternativas, na qual o supervisor oferece um número limitado de alternativas diferentes para lidar com um ponto selecionado da lição dada pelo professor-aprendiz, com o objetivo de desenvolver nele "uma consciência das opções envolvidas nas decisões sobre o quê e como ensinar" (p.108). Por fim, a opção não-diretiva é aquela na qual o elemento-chave é exatamente a relação entre o professor-aprendiz e o supervisor, criando um diálogo que abre espaço para que o professor-aprendiz encontre suas próprias soluções e seja seu próprio árbitro, ao mesmo tempo em que permite que o supervisor participe desse processo, contribuindo com sua experiência e conhecimento, sem, contudo, direcionar as conclusões do professor-aprendiz.

Focalizando também a interação na prática de ensino, Gebhard (1990a) faz um estudo etnográfico de sete professores inexperientes, descrevendo as mudanças de comportamento que resultaram da interação entre os participantes da pesquisa (os professores-aprendizes, o professor educador e os alunos). Gebhard conclui que "a interação fornece aos professores-aprendizes chances de falar sobre a sua maneira de ensinar" (p. 124), criando oportunidades para mudança.

Gebhard (1990b) discute seis modelos diferentes de supervisão de professores de inglês como LE. A exemplo de Freeman (1990), a discussão de Gebhard também se baseia no papel do supervisor enquanto educador e no valor da interação como catalizadora do processo de desenvolvimento do professor. O modelo de supervisão diretiva é apresentado como exemplo do tipo de supervisão tradicionalmente utilizado por supervisores, embora apresente vários problemas. Na visão do autor, um desses problemas é que esse modelo tende a provocar no professor-aprendiz, ou seja, aquele que está sendo supervisionado, um sentimento de inferioridade em relação ao seu supervisor, o que pode diminuir sua auto-estima. Além disso, o papel do supervisor nesse modelo pode representar uma ameaça para o professor-supervisionado, colocando-o numa posição de defesa em relação aos julgamentos feitos pelo supervisor. Para Gebhard, ao escolher esse tipo de supervisão, o supervisor corre o risco de restringir ou mesmo retardar o progresso de seus supervisionados. Como alternativa, Gebhard discute outros cinco modelos: supervisão alternativa, supervisão não-diretiva, supervisão colaborativa, supervisão criativa e supervisão de auto-ajuda ou exploratória. Os dois primeiros tipos (supervisão alternativa e não-diretiva) são idênticos às opções oferecidas em Freeman (1990), já discutidas. Já na supervisão colaborativa, o supervisor participa ativamente de qualquer decisão a ser tomada juntamente com o professor sem, contudo, direcioná-lo. A supervisão criativa, por sua vez, pode ser uma combinação de vários ou alguns dos outros modelos de supervisão. Por fim, a supervisão de auto-ajuda ou exploratória pretende proporcionar "oportunidades tanto para os professores quanto para os supervisores (...) para atingirem uma consciência a respeito da sua forma de ensinar através da observação e da exploração" (Gebhard, 1990b:163).

\section{A Relação Pesquisador-Pesquisado}


Pica (2000) ressalta que, desde que as pesquisas em sala de aula tiveram início, a relação existente entre professores e pesquisadores passou por vários estágios. Contudo, apenas recentemente essa relação, por vezes conturbada, passou a ser alvo da preocupação de autores e pesquisadores em Lingüística Aplicada. A partir dos anos 70, os professores passaram a ver as pesquisas como parte da base de conhecimento de sua profissão, funcionando como fonte de conhecimento. Com o passar dos anos, a relação entre professores e pesquisadores evoluiu, chegando a um estágio de colaboração e complementariedade.

Nas pesquisas em que o professor de LE é o foco de interesse, a questão da relação entre professor e pesquisador é de crucial importância, já que o professor passa a ser o principal informante da pesquisa. Desde o início, essa relação foi caracterizada por uma aparente assimetria entre os papeis do professor-pesquisado e do pesquisador. A princípio, os pesquisadores buscavam descrever o comportamento dos professores na sala de aula (Freeman, 1996). Nessa época, o papel do professor enquanto informante das pesquisas era puramente passivo, já que sua contribuição se limitava a permitir que um pesquisador ou observador assistisse a suas aulas.

Num segundo momento, quando predominam as pesquisas cognitivas (Freeman, 1996), o professor-informante assume um papel mais ativo à medida que não basta que ele abra as portas de sua sala de aula para o pesquisador ou observador. É preciso também que ele colabore com o pesquisador, fornecendo dados paralelos como, por exemplo, seus planos de aula, e participando de entrevistas ou respondendo questionários. No entanto, nesse tipo de pesquisa ainda predomina uma relação assimétrica entre professor e pesquisador, pois ao professor é delegado o papel de informar seus pensamentos, seus objetivos ou suas crenças, mas é o pesquisador quem detém o saber para analisar e julgar essas informações.

A tendência atual das pesquisas sobre o professor de LE, conforme proposta de Freeman (1996), pretende criar maior espaço para a voz do professor-informante, dando maior importância a suas próprias percepções e interpretações. Nesse tipo de pesquisa, a relação entre professor e pesquisador tende a se equilibrar, pois o pesquisador já não detém a verdade absoluta para a análise dos dados. O professor-pesquisado passa a ser, então, um colaborador em todos os níveis e os resultados da pesquisa vão depender, inclusive, da sua motivação para realizar análises e interpretações mais profundas e significativas.

Fazendo uma reflexão sobre os papéis exercidos por professores e supervisores, Gimenez (1999) discute a relação existente entre esses dois profissionais, dentro do contexto do Projeto $\mathrm{NAP}^{5}$, preocupando-se em estabelecer uma relação mais simétrica entre professores e pesquisadores. A autora afirma que os pesquisadores raramente demonstram humildade em suas relações com o professor. Incluindo-se entre esses pesquisadores, ela diz:

"Tornamo-lo sujeito de nossas pesquisas, objeto de nossas descobertas e pouco freqüentemente nossos companheiros na 'pronúncia' do mundo. Ao contrário, geralmente nos consideramos superiores, seja ao submetê-los ao crivo de nosso aparato teórico, seja ao elaborarmos implicações para o seu agir. Nosso modelo tem sido essencialmente bancário, procurando respostas que nós mesmos diremos, e as quais são avaliadas por nós mesmos." (Gimenez, 1999: 14). 
A autora sugere que os pesquisadores tornem a busca pelo conhecimento mais aberta à contribuição do professor, de forma que esse conhecimento deixe de ser visto como hierarquizado e abstrato, o que levaria à construção de uma relação diferenciada com o professor. Reis (1999) sugere que essa relação seja baseada na confiança, e ressalta que o objetivo dos assessores do projeto NAP é "ajudar o professor a se tornar cada vez mais consciente e crítico de sua prática" (Reis, 1999: 37), levando-o a uma possível e almejada autonomia.

A sugestão dessas autoras, então, é de que a relação entre professor e pesquisador deve basear-se na confiança que ambos cultivam entre si. Outros autores também consideram a confiança uma questão fundamental entre o pesquisador e seu informante. Gebhard (1990a), por exemplo, sugere que a atitude do pesquisador ou supervisor deve revelar uma postura não-avaliativa, e que o objetivo não deve ser julgar o professor ou sua maneira de ensinar, o que permite o estabelecimento de uma relação de confiança entre o professor e o pesquisador/supervisor.

Almeida Filho (1997) vai mais além, e adota conceitos vygotskianos para definir a relação entre o professor em desenvolvimento e seu observador. $\mathrm{O}$ autor sugere que $\mathrm{O}$ professor que deseja desenvolver-se profissionalmente deve estabelecer sua própria agenda de observação, decidir como avaliar aspectos da sua maneira de ensinar e "quais ações adotar para encaminhar quais mudanças e porque" (p. 34). Essa atitude é chamada de "formação auto-sustentada do professor" e nela o observador assume o papel de "colaborador, tutor esclarecido e experiente no sentido de Vygotsky" (ibid.). Almeida Filho se refere ao conceito vygotskiano de "parceiro mais experiente", Para Vygotsky, o papel da interação no aprendizado da criança é fundamental na medida em que uma criança pode conseguir realizar tarefas cuja complexidade se encontra além do seu nível de desenvolvimento real através da ajuda de uma pessoa mais velha e mais experiente (Lantolf \& Appel, 1994; Rego, 1994). Esse conceito, que envolve uma relação chamada de "scaffolding", tem sido recentemente utilizado nas pesquisas sobre aquisição de LE. A sugestão de Almeida Filho (1997) traz o conceito para o campo da formação do professor. Essa idéia, contudo, não é totalmente nova. Freeman (1990) já sugeria que o professoraprendiz pode beneficiar-se das percepções e comentários do professor-educator, e aprender a ensinar melhor, e Wallace (1991) também sugere uma abordagem colaborativa para a supervisão, com o objetivo de desenvolver a autonomia do professor através da reflexão e da auto-avaliação.

Esse tipo de relação, no entanto, não parece ser comumente encontrada entre professores e pesquisadores no meio acadêmico, nem tampouco entre professores e supervisores em escolas de ensino fundamental e médio ou institutos de ensino de línguas (Gimenez, 1999). Porém, é preciso que se reconheça que a forma tradicional de se supervisionar ou observar professores não traz grandes contribuições para o seu desenvolvimento profissional. Ao contrário, muitas vezes as atitudes avaliativas de supervisores e pesquisadores podem causar sentimentos de inferioridade e medo no professor, prejudicando sua criatividade e auto-confiança (Gebhard, 1990b). Vale a pena, portanto, investir em uma relação mais equilibrada entre professores e supervisores ou pesquisadores em busca de um maior desenvolvimento profissional para todos os participantes. 


\section{Metodologia da Pesquisa}

O desenho desta pesquisa baseou-se em estudos teóricos e empíricos sobre pesquisa em sala de aula e sobre o professor de LE, adotando uma visão interpretativista e êmica (Freeman, 1996). O objetivo principal da pesquisa foi buscar uma compreensão global sobre como o professor de LE em formação interpreta sua sala de aula e os eventos que nela acontecem. A pesquisa procurou fomentar a reflexão crítica da informante sobre sua atuação dentro da sala de aula, de forma a promover seu desenvolvimento profissional. Para esse fim, foi realizado um estudo de caso, tendo como informante uma professora de inglês do Centro de Extensão da FALE/UFMG (CENEX) ${ }^{7}$ que, na época da pesquisa, cursava o oitavo período do curso de Letras-Inglês. Carolina, nome fíctício por ela escolhido, lecionava como estagiária no curso básico de inglês para adultos do CENEX e não tinha experiência anterior de sala de aula.

Entrevistas de retrospecção foram utilizadas como principal instrumento para coleta de dados. As aulas da informante foram gravadas em vídeo durante um mês e, em seguida, Carolina reunia-se com a pesquisadora para sessões de visionamento e entrevistas de retrospecção, onde refletia sobre suas aulas, com o auxílio do vídeo. Os trechos das gravações eram ora selecionados pela pesquisadora ora pela própria informante e não havia um roteiro fixo de perguntas para as sessões de visionamento - os trechos do video eram observados e comentados pela professora participante, com breves perguntas ou comentários da pesquisadora conforme fosse necessário. Durante essas entrevistas a pesquisadora procurou sempre assumir uma atitude colaborativa e não-avaliativa para com a informante, seguindo os princípios da supervisão não-diretiva (Freeman, 1990; Gebhard, $1990 \mathrm{a}$ e b). Foram realizadas, então, oito gravações de aulas consecutivas e oito entrevistas, que geralmente ocorriam no dia seguinte às gravações, com duração média de duas horas cada uma. Essas entrevistas tiveram como objetivo fomentar a reflexão crítica da informante sobre sua atuação dentro da sala de aula a fim de promover o seu desenvolvimento profissional. O conteúdo dessas entrevistas foi categorizado, expandindo as categorias reflexivas de Richards $(1998)^{8}$. A relação final das categorias utilizadas para categorizar os dados desta pesquisa encontra-se no Anexo I.

Terminadas as gravações e entrevistas, Carolina respondeu a um questionário de avaliação final (Anexo II), cujo objetivo foi verificar as possíveis influências da metodologia utilizada na pesquisa sobre a sua prática, como forma de triangular os dados das entrevistas de retrospecção. Este trabalho teve por objetivo principal, então, discutir as mudanças evidenciadas no comportamento de Carolina em relação à sua prática a partir da auto-observação e a avaliação dela sobre sua participação na pesquisa. A próxima sessão discute essas mudanças observadas no comportamento da informante, citando trechos das entrevistas e respostas do questionário de avaliação final.

\section{Auto-observação, Conscientização e Mudança}

O objetivo deste trabalho foi, portanto, revelar evidências de possíveis mudanças no comportamento da informante devido à sua participação na pesquisa. Não se pode dizer que a metodologia da pesquisa tenha provocado grandes mudanças no comportamento da informante. Porém, foram encontradas nos dados algumas evidências que apontam para mudanças em seu comportamento que podem ser atribuídas à sua participação nesta 
pesquisa. Essas mudanças ficam evidentes quando se analisa o conteúdo das declarações da informante no decorrer das entrevistas de retrospecção.

Um primeiro comportamento que Carolina parece ter modificado devido à sua participação nesta pesquisa se refere à sua maneira de fazer perguntas às alunas. Logo no início da coleta de dados, foi possível perceber que, ao dirigir perguntas às suas alunas, Carolina adotava um tipo de comportamento: especificamente, ela parecia dirigir a maioria de suas perguntas às alunas mais fluentes. Logo na primeira entrevista, como se vê do trecho citado em seguida ${ }^{9}$, a própria informante percebe a existência de algum problema na sua maneira de dirigir perguntas às alunas, porém ainda não consegue identificar a causa:

P - "Você disse que já pensou sobre a sua maneira de fazer perguntas. O que você achou?

I - Ah, é ... que ... às vezes eu faço a pergunta meio ... nem é uma pergunta direta, não, eu falo o começo do que eu quero saber, pra elas continuarem falando, então às vezes não fica muito claro. Acho que eu tinha que ser mais clara nesse tipo de pergunta. Mas, também ... vamos supor que eu perguntei direito, tudo certo, expliquei, mas, às vezes, a aluna mesmo que, por algum motivo, está dispersa, ou está lendo o exercício mesmo, não está prestando atenção, e num pega direito qual foi a pergunta ou o que foi que eu expliquei pra fazer o exercício. Então, tem esses dois lados, eu não explico direito, que eu acho que esse é um problema de ... fluência ...

$\mathbf{P}$ - Fluência sua?

I - Eu acho.

$\mathbf{P}$ - Você acha? Você acha que é do seu domínio da língua?

I - É, eu acho que é no meu domínio da língua. Mas, também, a maneira de eu fazer a pergunta. Em vez de eu fazer, é: "ela parece ... o que?", eu devia fazer já a pergunta certa: "o que ela parece?" Né, fazer a pergunta certa ...

$\mathbf{P}$ - Você acha que é a maneira como você estrutura a pergunta, né?

I - É ... É, pode nem tanto ser o problema da fluência, acho que é o meu jeito mesmo de falar, eu ... falo dessa maneira mesmo. Pode ser também ... não é necessariamente o problema da língua."

Primeira Entrevista - p. 6

Nesse trecho, então, Carolina menciona que já havia percebido algum problema na sua maneira de fazer perguntas às alunas. Para ela, a causa do problema parece ser, a princípio, seu pouco domínio da língua inglesa, mas logo a seguir ela percebe que a causa está no seu "jeito de falar". Para ajudá-la a refletir mais sobre o assunto, a pesquisadora fala sobre sua percepção do evento, provocando novas reflexões:

$\mathbf{P}$ - "Uma coisa que eu noto também sobre as perguntas é como é a resposta delas [as alunas]. Eu reparo que você faz a pergunta e ... elas não respondem. Então, como você vê isso? Você acha que é porque elas não sabem responder ... quer dizer, nesta parte do vocabulário, por exemplo, você foi dando várias palavras novas. Então você pergunta aqui na letra "c", "sobre essa moça da foto "c", o que vocês podem falar sobre ela?" Aí, elas só falam do "dark, short hair", né. E, depois você continua dando o resto da descrição. Por que você acha que acontece isso?

I - Por causa ... acho que do nível delas, esse negócio de adjetivo pra descrever pessoas ... é sempre mesmo, fica só no cabelo, ou no olho e pronto, então ... 
$\mathbf{P}$ - Então você acha que tem que fornecer mais vocabulário pra elas?

I - É, é."

Primeira Entrevista - p. 7

Nesse trecho, Carolina chega à conclusão de que há também um outro problema, cuja causa é a falta de vocabulário por parte das alunas do curso e que se revela na ausência de resposta das alunas às suas perguntas. Como observadora, foi possível perceber que apenas as alunas mais fluentes respondiam às perguntas da professora. Ao refletir sobre isso, Carolina a princípio avalia que isso se deve ao fato de que as outras alunas têm mais dificuldades com a língua. Com o decorrer da entrevista e ao observar suas próprias atitudes no vídeo, Carolina começa a fazer reflexões mais profundas sobre sua atuação. Ela, então, começa a perceber que sua postura na sala de aula parece influenciar esse comportamento passivo de suas alunas. $O$ trecho a seguir mostra $o$ momento em que, com a ajuda do vídeo, ela começa a perceber essa influência:

$\mathbf{P}$ - "É, eu reparei desde o início que quando você pergunta são sempre as mesmas alunas que respondem. E as duas ali do cantinho raramente participam.

I - É, a J e a MF, são as duas que têm dificuldade.

$\mathbf{P}-\mathrm{Ah} \ldots$ tá.

[Outros comentários não relevantes para essa questão]

I - Agora, também, esse negócio dela [a aluna J] não responder, é outra coisa também que eu já pensei, e agora com o vídeo aqui eu lembrei, que eu fico muito ... é ... virada pras duas lá [as duas melhores]. Isso é coisa que a gente na hora não percebe, pelo menos comigo, mas ... durante a aula mesmo outro dia eu percebi. Que eu fico só virada pra lá. Mas, aí, ao mesmo tempo, ... eu tenho que dar um jeito, também, de fazer elas [as alunas mais fracas] participarem mais, eu estou achando que está faltando isso.

$\mathbf{P}$ - Então, você percebeu que você fica mais virada pra elas [as alunas mais fluentes]?

I - É, a minha posição, minha postura ...

$\mathbf{P}$ - E por que você acha que isso acontece?

I - Ai ... eu não sei, ah, eu acho que é por causa ... eu não sei se é ... meu medo de elas acharem ... de elas ficarem ... constrangidas comigo, de eu ficar mandando elas falarem.

$\mathbf{P}$ - As que não falam?

I - É. Eu acho, talvez seja por isso de eu ficar virada pra lá ... Aí acaba que eu fico virada pra lá por causa disso, e ... eu acabo que eu não faço elas participarem. E ... deixa eu ver ... acho que é isso. É, acho que é isso, o que eu estou notando que eu tenho que acabar (risos)."

Primeira Entrevista - p. 12-3

Durante a segunda entrevista, esse assunto é novamente abordado e Carolina já começa a procurar maneiras de solucionar o problema, como mostra o seguinte trecho:

$\mathbf{P}$ - "E a maneira como você pergunta, voltando àquilo que a gente estava falando da vez passada. Você está jogando a pergunta pra todo mundo, e aí responde I - É. quem quer ou quem sabe, né?

$\mathbf{P}-\mathrm{O}$ que você está achando disso agora? 
I - Ah, eu acho que deve ser melhor se eu (risos) procurar direcionar mais [as perguntas]. Porque ... ainda continua assim mesmo ... se eu jogar a pergunta, elas tendem a ficar acomodadas."

Segunda Entrevista - p. 9

A partir da aula seguinte a essa discussão, Carolina começa a mudar seu comportamento, aplicando na sala de aula suas reflexões feitas durante as entrevistas. $\mathrm{O}$ retorno é imediato, ou seja, ela passa a direcionar mais suas perguntas e como conseqüência obtém maior participação de suas alunas, inclusive daquelas que eram consideradas tímidas e com pouco domínio da língua inglesa. Além disso, Carolina assume uma nova postura frente à sala de aula: ela passa a virar-se para todas as alunas, procurando olhar para cada uma delas. Carolina percebe essas mudanças e comenta sobre isso na terceira entrevista, como se vê nos trechos a seguir:

I - "Nesse primeiro exercício, que elas têm que ir falando o que elas vêem na figura ... eu acho que a MF, que eu estava notando que ela não participava muito, eu acho que ela já participou mais. Na hora eu estava pensando no que eu já tinha refletido, né, de dirigir mais a pergunta pra elas que não falam muito, aí eu acho que ... que deu certo, começou a dar certo, ela já falou mais (...) inclusive foi ela que falou primeiro, junto com as outras."

Terceira Entrevista - p. 2

I - “... O que eu notei é que eu estou procurando mais olhar e o jeito do corpo mesmo, dar mais atenção também pro lado de cá, que eu não estava dando muita, à $\mathrm{J}$, e à sala toda, elas todas, né, às cinco, todas."

Terceira Entrevista - p. 3

A partir daí, Carolina passa a assumir um novo comportamento dentro de sua sala de aula, ou seja, ela passa a dar mais atenção a todas as alunas, dirigindo suas perguntas a alunas específicas, ao invés de fazer perguntas ao grupo todo, o que permite que todas as alunas participem da aula. Além disso, ela também modifica sua postura, passando a olhar e se virar para todas as alunas, e não apenas para aquelas mais fluentes.

Essa mudança no seu comportamento, além de estar retratada nas gravações em vídeo das aulas subseqüentes às discussões apresentadas acima, também pode ser percebida através das respostas da informante ao questionário de avaliação. Ao responder à pergunta $\mathrm{n}^{\circ} 5$, por exemplo, a informante declarou:

"Acredito que a reflexão sobre minhas aulas teve um efeito positivo sobre minha maneira de ensinar. Passei a ficar mais atenta a minha postura em sala de aula, tomando o cuidado de não me voltar mais para um (uns) aluno(s) que outros."

Questionário de Avaliação, resposta à pergunta 5.

Ao responder à pergunta $n^{\circ} 9$, Carolina volta a tocar nesse assunto, o que mais uma vez comprova que houve mudança no seu comportamento em decorrência da sua participação nesta pesquisa.

"Em decorrência da auto-observação, continuo a estimular os alunos a participarem de forma ativa e motivadora, porém passo a tomar mais cuidado para não estimular uns mais que os outros." 


\section{Questionário de Avaliação, resposta à pergunta 9.}

Um outro comportamento da informante no qual uma mudança foi identificada se refere ao uso da tradução para esclarecer dúvidas das alunas ou para apresentar vocabulário. Durante a segunda entrevista, Carolina fala sobre que técnicas um professor pode usar para esclarecer o significado de palavras. No trecho transcrito a seguir, Carolina apontou várias técnicas possíveis para apresentação de vocabulário novo ou para esclarecer palavras desconhecidas. Sobre a tradução, ela afirmou que é uma técnica que deve ser usada somente em último caso.

$\mathbf{P}$ - "Bom, nessa parte, então, você está tentando explicar o significado, né, através de definição e gestos, etc. Que abordagens o professor pode usar pra esclarecer o significado de palavras desconhecidas pro aluno?

I - Ah, palavra desconhecida ... eu acho que ... sinônimo, é muito bom pra ... apresentar uma palavra desconhecida. Mas, também, quando fica difícil de dar um sinônimo, a imagem é o melhor: você associar com uma imagem, ou um exemplo que seja fácil pro aluno.

$\mathbf{P}$ - Um desenho, assim?

I - É ... além da imagem, de um desenho, ou mesmo fazer ele associar a imagem por definição, ou por gesto, igual imitando um pouco, por exemplo ...

$\mathbf{P}-\mathrm{E}$ a tradução?

I - Ah, tradução, acho que em último caso, e só também se for uma palavra complicada que você não acha uma imagem, não consegue desenhar, não tem jeito de ser por gesto, né, então, aí dá a tradução."

Segunda Entrevista - p. 3

Essa discussão sobre o assunto não se prolongou, no entanto, durante a sexta entrevista a mesma questão é retomada:

$\mathbf{P}$ - "Teve uma vez, logo nas primeiras entrevistas, que eu lembro que eu te perguntei sobre tradução. Aí, sua resposta foi assim: "ah, tradução só em último caso".

I - Uhum.

$\mathbf{P}$ - E agora, já tem umas duas fitas [vídeo] ou talvez até três, que eu tenho notado que tem aparecido mais tradução, como agora. O que aconteceu?

I - Eu acho que pra ficar mais claro ... porque também eu não fui direto na tradução, eu tentei ... dei uns exemplos, expliquei, e aí eu quis falar no português pra comparar, pra ficar mais claro. Porque isso daí é a língua, né, igual a gente também tem várias maneiras de falar a mesma coisa. Então ... acho que ajudou a tradução, acho que foi ... foi bom."

Sexta Entrevista - p. 4

Nesse trecho, percebe-se claramente que o comportamento da informante já vinha se alterando desde aulas anteriores. Não se pode afirmar nesse caso que a mudança detectada foi provocada por discussões ou reflexões feitas durante as entrevistas, mas percebe-se que houve uma mudança. Contudo, é possível que apenas o fato de ter expressado suas convicções sobre o uso da tradução na sala de aula tenha levado a informante a refletir sobre o assunto, e conseqüentemente tenha provocado a alteração de seu comportamento. 
Em suas respostas ao questionário de avaliação, Carolina reconhece a importância da sua participação nesta pesquisa para o seu desenvolvimento profissional. Ao responder às perguntas $n^{\circ} 1,4,6$ e 7 do questionário, apresentadas a seguir, ela deixa claro que considerou válida a sua participação na pesquisa e tece comentários sobre a influência da metodologia utilizada na sua maneira de ensinar.

"É uma experiência bastante produtiva e gratificante e, portanto, de grande utilidade, na medida em que posso acompanhar melhor o processo de ensino/aprendizagem. Não só observo e reflito sobre minhas atitudes, mas também sobre as dos alunos."

Questionário de Avaliação, resposta à pergunta 1.

"Aprendi melhor como observar e refletir sobre meu ensino, pois eu mesma deveria abranger diferentes aspectos práticos e/ou teóricos da aula, na medida em que justificava minhas atitudes. Dessa maneira, pude lembrar, pensar e repensar teoria/prática, considerando o que era positivo ou não para melhorar meu desempenho. Consequentemente, aprendi a lidar melhor com a prática de ensino, percebendo teorias que se aplicam ou não, bem como identificando e avaliando criticamente métodos e técnicas que funcionam ou não na aula observada, e que podem servir para outras aulas."

Questionário de Avaliação, resposta à pergunta 4.

"Também sobre meu processo de aprender a ensinar, esta experiência teve um efeito positivo. Constatei como é útil refletir sobre minhas aulas para poder ensinar melhor, porque posso perceber o que é mais eficaz e produtivo no ensino/aprendizagem. Acredito, ainda, que esta experiência de auto-observação acelera o bom desenvolvimento do processo de aprender a ensinar."

Questionário de Avaliação, resposta à pergunta 6.

"Houve muita mudança. Sou mais consciente e segura do que faço; acabou, ou pelo menos tornou-se mais controlável, o receio de não proporcionar uma boa aula, ou de não corresponder apropriadamente às necessidades do aluno, porque tenho a possibilidade de checar, confirmar, ou tirar qualquer dúvida com relação ao que aconteceu na sala de aula, no momento mais tranqüilo do que o da aula, que é o de auto-observação. Durante a aula, estou envolvida com vários aspectos ao mesmo tempo, sendo mais difícil de perceber se tomo as decisões mais certas. Dessa maneira, sou menos ansiosa para alcançar logo resultados - para perceber o produto - , acompanhando melhor o processo. Outra mudança é a de que posso avaliar melhor meu planejamento, considerando formas diferentes de abordar uma mesma lição. E, definitivamente, tenho o que não tinha anteriormente: 'a ferramenta' (a auto-observação) para fazer com que possa melhorar cada vez mais minha maneira de ensinar."

Questionário de Avaliação, resposta à pergunta 7.

Carolina revela, ainda, sua crença de que a mudança detectada em seu comportamento durante sua participação na pesquisa será duradoura, ou seja, ela acredita que, no futuro, seu comportamento sempre apresentará reflexos do tempo em que participou da pesquisa, como se percebe por sua resposta à pergunta $\mathrm{n}^{\circ} 10$ do questionário: 
"Acredito que meu desempenho futuro será diferente, na medida em que posso acompanhar o desenvolvimento de minhas aulas com mais eficiência, facilitando e adequando melhor o planejamento, sendo possível perceber com mais cuidado as reações dos alunos e suas intenções."

Questionário de Avaliação, resposta à pergunta 10.

A informante declara também, em suas respostas ao questionário, que sua participação na pesquisa trouxe benefícios adicionais para seus alunos. Isso fica claro em sua resposta à pergunta $\mathrm{n}^{\circ} 11$ do questionário:

"Acredito que meus alunos também foram beneficiados com esta pesquisa. Como podia verificar minhas atitudes na sala de aula e refletir sobre o que seria importante para melhorar meu ensino - melhorando o aprendizado deles - as aulas estavam tornando-se mais adequadas. Além disso, acredito que foi mais uma motivação, porque notei que as alunas gostaram, e se sentiram bem em colaborar com uma pesquisa, ou como disse uma delas 'sou importante'."

Questionário de Avaliação, resposta à pergunta 11.

Ao responder à pergunta $\mathrm{n}^{\circ} 14$ do questionário de avaliação, Carolina volta a ressaltar o quanto sua participação na pesquisa foi importante para seu desenvolvimento profissional. Ela relata, inclusive, que passou a utilizar seu próprio gravador durante suas aulas para dar continuidade ao processo de reflexão sobre sua prática que havia iniciado durante sua participação na pesquisa.

"Sou muito grata por ter tido a oportunidade de participar desta pesquisa, que me ajudou muito a crescer profissionalmente. A pesquisa foi tão importante para mim, que passei a usar meu gravador na sala de aula para poder refletir sobre meu ensino, enquanto não posso usar uma filmadora."

Questionário de Avaliação, pergunta 14.

Como foi demonstrado, através da auto-observação, ou seja, ao observar sua própria atuação dentro da sala de aula na gravação em vídeo, a informante teve a oportunidade de refletir sobre seu desempenho e sobre os eventos ocorridos durante sua aula. Ao discutir suas reflexões durante as entrevistas de retrospecção, Carolina encontrou um ambiente propício para o seu desenvolvimento, fornecido pela relação de confiança que se estabeleceu, graças ao uso da opção não-diretiva, conforme as sugestões de Freeman (1990) e Gebhard (1990a, b), o que permitiu a ocorrência das mudanças em seu comportamento já citadas. Ao responder à pergunta $n^{\circ} 2$ do questionário de avaliação, Carolina tece comentários sobre a atitude da pesquisadora durante as entrevistas, que certamente influenciou todo o seu processo de reflexão. Em sua resposta, ela diz o seguinte:

"Os aspectos positivos dessa experiência foram o de adquirir o hábito de autoobservação e reflexão de minhas aulas; o de melhorar meu desempenho como professora; o de participar de um processo de pesquisa; e o de 'trabalhar' com você que é uma pessoa incentivadora e compreensiva."

Questionário de Avaliação, pergunta 2. 
Embora tenha sido demonstrado que a informante passou por um processo de mudança durante sua participação nesta pesquisa, não é possível afirmar que a metodologia da pesquisa tenha provocado grandes ou numerosas mudanças no comportamento da informante, pois foram encontradas evidências de apenas duas alterações no seu comportamento. Esse número pode ser atribuído ao curto prazo de duração da pesquisa, cuja coleta de dados foi realizada em apenas um mês. Porém, é justamente devido a esse curto prazo de duração que se pode afirmar que o pequeno número de mudanças ocorridas no comportamento da professora-informante é significativo.

Os trechos citados comprovam que Carolina modificou seu comportamento no decorrer da coleta de dados para esta pesquisa. Mais importante que isto, esses trechos evidenciam que as mudanças no comportamento da informante foram provocadas pelo tipo de reflexão que ela realizou durante sua participação na pesquisa e pelo ambiente favorável em que essas reflexões foram feitas. Essa é uma constatação que comprova que a metodologia utilizada na coleta de dados favorece não só a reflexão do professorinformante como também o seu auto-desenvolvimento. A análise revelou, então, que a metodologia utilizada para a coleta dos dados da pesquisa e a postura não-diretiva adotada pela pesquisadora favoreceram a reflexão crítica da informante, contribuindo para o seu desenvolvimento profissional. Com base nos resultados da pesquisa, o modelo para formação do professor de LE de Wallace (1991) foi ampliado.

\section{Um Modelo Ampliado de Reflexão do Professor}

Como foi visto, Wallace (1991) propôs um modelo reflexivo para a formação do professor de língua estrangeira. A pesquisa aqui relatada teve como referencial teórico o modelo proposto por Wallace (ibid). Assim, um dos objetivos da pesquisa foi promover a reflexão da informante sobre suas aulas, para que ela, através dessa reflexão, alcançasse um maior desenvolvimento profissional. Contudo, a partir da realização da pesquisa, o modelo pode ser ampliado.

Conforme já discutido na seção anterior, a metodologia utilizada na pesquisa promoveu a reflexão da informante sobre a sua prática de sala de aula. O uso do vídeo durante as entrevistas de retrospecção, além de estimular as lembranças da informante sobre os eventos ocorridos durante a aula, permitiu que ela refletisse sobre esses eventos. A auto-observação, através do vídeo, permitiu que a informante realizasse reflexões cada vez mais profundas sobre a sua atuação dentro da sala de aula. Durante as entrevistas de retrospecção, foi possível perceber que, cada vez que um determinado aspecto do seu desempenho era abordado, Carolina aprofundava suas reflexões. Assim, na primeira vez que determinado assunto era discutido, ao refletir, Carolina fazia um certo número de considerações a respeito. Já em entrevistas subseqüentes, quando o mesmo assunto era retomado, ela fazia reflexões cada vez mais aprofundadas, sempre em busca de respostas e soluções para os problemas por ela identificados. Os trechos citados na seção anterior exemplificam bem esse aprofundamento percebido nas reflexões da informante. Assim, a partir dessa percepção, sugere-se algumas modificações no modelo proposto por Wallace (ibid), de forma a ampliar seu escopo e ilustrar mais facilmente o processo de reflexão de uma professora em formação, como ilustra a figura 2 a seguir. 


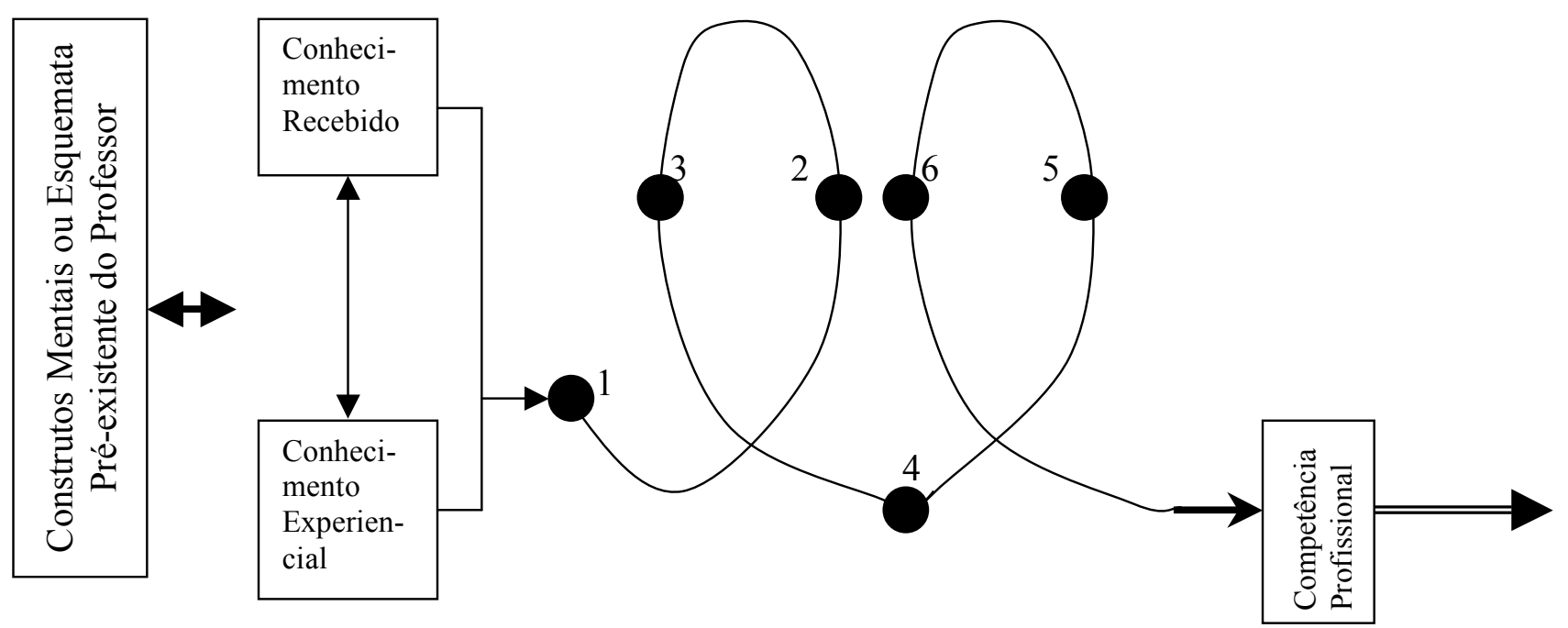

Figura 2 - Ampliação do Modelo Reflexivo de Wallace (1991)

As alterações propostas para o modelo levam em consideração que o aumento da competência profissional do professor realimenta o processo de reflexão que, por sua vez, passa a ser feito com mais intensidade e em um nível mais aprofundado. O estágio de desenvolvimento profissional deixa, então, de ser um ciclo fechado como na proposta de Wallace (ibid), apresentada anteriormente, e passa a ser um espiral que leva sempre a uma maior competência profissional.

A figura acima permite uma visualização mais completa do desenvolvimento do professor, pois mostra como seu desempenho evolui em busca de um constante aperfeiçoamento, a partir da experiência prática e da reflexão. Elementos centrais da proposta de Wallace (ibid), porém, são conservados, como aquilo que o professor traz para o processo de reflexão, ou seja, seus construtos mentais ou esquemata pré-existente, seu conhecimento recebido e seu conhecimento experiencial. A tão almejada competência profissional também continua a ser um alvo móvel que se afasta cada vez que o professor avança em sua direção.

Segundo esse modelo, é possível promover a reflexão do professor sobre suas aulas, com o objetivo de ajudá-lo em sua busca constante por desenvolvimento. O uso do vídeo favorece a reflexão do professor sobre sua prática. Cada vez que o professor se observa no vídeo, tem a oportunidade de refletir sobre a sua atuação, identificando problemas e buscando soluções. $\mathrm{O}$ uso da opção não-diretiva por parte da pesquisadora contribui para a criação de uma atmosfera segura para o processo de reflexão do professor. Dessa maneira, o professor sente-se confortável para realizar suas reflexões em níveis cada vez mais profundos, visando sempre a uma maior competência profissional.

\section{Implicações dos Resultados da Pesquisa}

Os resultados obtidos nesta pesquisa trazem implicações relevantes tanto para o campo da formação do professor de LE quanto para a relação entre pesquisador e professor pesquisado. 


\section{Implicações para a Formação do Professor de LE}

A formação do professor de LE no Brasil tem sido comumente realizada na esfera dos cursos de Letras das universidades e faculdades do país (Almeida Filho, 1997). Essa formação muitas vezes não é suficiente para que o professor que se inicia na profissão de ensino de línguas se sinta em condições de tomar decisões e fazer escolhas informadas sobre sua prática, limitando-se a aplicar em sua sala de aula as técnicas e procedimentos aprendidos exatamente como foram recomendados por seus manuais de ensino ou por seus professores (Moita Lopes, 1996). Essa situação pode ser modificada através do uso de uma abordagem para a formação do professor que o incentive a adotar uma postura crítica em relação ao seu próprio trabalho, proporcionando-lhe alternativas para o seu próprio desenvolvimento profissional.

$\mathrm{Na}$ análise apresentada, os procedimentos metodológicos utilizados para a coleta dos dados desta pesquisa favorecem o desenvolvimento profissional do professor de LE. As gravações em vídeo funcionam como um instrumento para auto-observação e permitem que o professor relembre os eventos ocorridos em sua aula, analisando-os a partir de um outro ponto de vista: o ponto de vista de um observador. Nessa condição, o professor em formação pode refletir criticamente sobre os eventos ocorridos em sua sala de aula, detectando problemas e procurando soluções. Essa reflexão crítica permite que o professor verbalize suas teorias e concepções sobre ensino/aprendizagem de LE à medida que justifica sua atuação na sala de aula, tornando-se consciente delas.

Vários autores têm sugerido que o professor em formação realize a auto-observação em colaboração com um parceiro, que pode ser um colega de trabalho, um supervisor ou um pesquisador (Freeman, 1990; Wallace, 1991; Almeida Filho, 1997; Baghin \& Alvarenga, 1997). Como já foi dito, esse colaborador deve assumir o papel de "parceiro mais experiente" na concepção de Vygotsky (Almeida Filho, 1997), auxiliando o professor em formação no seu processo de reflexão crítica sem, contudo, direcioná-lo. Esse processo de reflexão crítica e conscientização é o primeiro passo em direção às mudanças que se façam necessárias, pois promove o empoderamento e a autonomia do professor em busca de seu desenvolvimento profissional, principalmente quando ele pode contar com o apoio de um colaborador mais experiente.

$\mathrm{O}$ uso de uma abordagem que promova a reflexão crítica e a conscientização dos professores pode trazer benefícios para a formação do professor no âmbito dos cursos de Letras e mesmo no âmbito dos cursos de treinamento e desenvolvimento freqüentados por professores já graduados e experientes. A metodologia utilizada para a coleta de dados nesta pesquisa mostrou-se capaz de promover essa reflexão crítica que leva a uma prática de ensino informada e consciente. Assim, essa parece ser uma abordagem adequada para os cursos de formação de professores, pois através dela os professores formadores poderão contribuir para o desenvolvimento da consciência crítica e da autonomia dos professores em formação.

\section{Implicações para uma nova Relação Pesquisador-Pesquisado}

Ultimamente, a relação que se estabelece no decorrer de uma pesquisa entre pesquisadores e professores-pesquisados tem sido alvo de atenção. Nessa relação, encontrase freqüentemente uma acentuada assimetria entre os papéis do pesquisador e do professor, 
pois o primeiro é visto como detentor do saber, capaz de julgar os comportamentos e atitudes do segundo. $\mathrm{O}$ mesmo ocorre na relação hierárquica que se estabelece entre supervisores ou professores formadores e professores supervisionados ou em formação. Nesse caso, a relação entre os participantes apresenta-se geralmente sob um aspecto prescritivo, ou seja, os professores formadores e supervisores, na qualidade de especialistas, prescrevem a maneira como os professores em formação devem agir e as atitudes que devem tomar em cada situação (Ortenzi, 1999). Enfatiza-se, assim, um modelo que privilegia o treinamento dos professores em formação, que assumem o papel de consumidores do saber maior de seus supervisores ou dos resultados das pesquisas.

Vários autores, no entanto, sugerem que um maior equilíbrio entre os dois lados dessa relação seria bem mais proveitoso tanto para os resultados das pesquisas quanto para o desenvolvimento do professor em formação (Wallace, 1991; Freeman, 1996; Gimenez, 1999; Reis, 1999). Nesse caso, o professor-pesquisado sai de uma condição de passividade para assumir um papel mais ativo na sua relação com o pesquisador. Ao mesmo tempo, essa relação deixa de enfatizar o treinamento para privilegiar o desenvolvimento do professor, a medida que ele passa a ser visto como participante e colaborador.

Esta pesquisa apresenta um caminho alternativo para essa relação assimétrica e hierárquica comumente encontrada entre pesquisadores e professores pesquisados. Ao adotar as sugestões de Gebhard (1990a, b) e Freeman (1990), assumindo uma atitude nãodiretiva e não-avaliativa para com a informante, surgiu uma relação mais simétrica e colaborativa entre a informante e a pesquisadora. Os resultados obtidos foram compensadores para ambas as partes. Por um lado, a informante sentiu-se segura e à vontade para fazer reflexões sobre sua prática, muitas vezes se auto-avaliando, detectando seus problemas e procurando suas próprias soluções. Por outro lado, devido à esse sentimento de segurança proporcionado à informante, a pesquisadora obteve informações e interpretações às quais não teria acesso caso tivesse assumido uma outra atitude.

Portanto, é importante investir em uma nova relação mais simétrica e menos hierarquizada, que esteja fundamentada na confiança e na colaboração entre as partes, o que certamente trará benefícios para todos. Como ressaltou Ortenzi (1999: 45), "permanece o desafio de deixarmos de lado os papéis de 'experts' e de consumidores para nos colocarmos como parceiros pensando juntos sobre situações de ensino."

\section{Conclusão}

Esta pesquisa investigou a prática de uma professora de inglês como LE e sua visão sobre a sua sala de aula, tendo por objetivo fomentar o processo de reflexão crítica da informante através de entrevistas de retrospecção. Essas entrevistas foram estimuladas por gravações em vídeo das aulas da informante a fim de proporcionar-lhe oportunidades para o seu desenvolvimento profissional.

A análise realizada a partir dos dados coletados revelou evidências de mudança no comportamento da informante. Foram discutidos dois pontos que comprovam que o comportamento da informante se modificou durante sua participação nesta pesquisa, argumentando-se que a metodologia utilizada durante a coleta dos dados pode ter influenciado essas mudanças.

Por fim, a partir desses resultados, o modelo reflexivo para a formação do professor, proposto por Wallace (1991), foi ampliado, e algumas alterações foram 
sugeridas. O modelo ampliado permite promover a reflexão do professor sobre sua prática diária, provocando mudanças em seu comportamento e contribuindo para $\mathrm{o}$ desenvolvimento profissional do professor em formação.

A análise final mostrou que, através da reflexão, o professor aprende a partir de sua própria prática de ensino. Esse aprendizado leva à mudanças que contribuem para o seu desenvolvimento profissional. Por fim, a análise dos dados mostrou também que a metodologia utilizada na pesquisa contribuiu favoravelmente para o desenvolvimento da prática de ensino de LE da informante, a medida que os procedimentos usados incentivaram seu processo de reflexão crítica. Os resultados obtidos trouxeram implicações tanto para a formação do professor de LE quanto para a relação entre pesquisador e professorpesquisado.

\section{Referências Bibliográficas}

ALMEIDA FILHO, J. C. P. Dimensões comunicativas no ensino de línguas. Campinas: Pontes, 1993.

Tendências na formação continuada do professor de língua estrangeira. APLIEMGE: Ensino \& Pesquisa, n.1, p. 29-41, 1997.

BAGHIN, D. C. M. \& ALVARENGA, M. B. A auto-observação do professor de língua estrangeira: instrumento para reflexão e mudanças. APLIEMGE: ensino \& pesquisa, n. $1, \mathrm{p}$. 53-8, 1997.

BARTLETT, L. Teacher development through reflective teaching. In: RICHARDS, J. C. \& NUNAN, D. (Ed.) Second language teacher education. New York: Cambridge University Press, 1990.

FREEMAN, D. Intervening in practice teaching. In: RICHARDS, J. C. \& NUNAN, D. (Ed.) Second language teacher education. New York: Cambridge University Press, 1990.

. Redefining the relationship between research and what teachers know. In:

BAILEY, K. \& NUNAN, D. (Ed.) Voices from the language classroom. New York: Cambridge University Press, 1996.

GEBHARD, J. G. (a) Interaction in teaching practicum. In: RICHARDS, J. C. \& NUNAN, D. (Ed.) Second language teacher education. New York: Cambridge University Press, 1990.

(b) Models of supervision: choices. In: RICHARDS, J. C. \& NUNAN, D. (Ed.) Second language teacher education. New York: Cambridge University Press, 1990.

GIMENEZ, T. Learners becoming teachers: an exploratory study of beliefs held by prospective and practising EFL teachers in Brazil. 1994. 346 f. Tese (Doutorado) Department of Linguistics and Modern English Language, Lancaster University.

Uma crítica da relação universidade/ensino fundamental e médio. In:

GIMENEZ, T. (Org.). Os sentidos do projeto NAP: ensino de línguas e formação continuada do professor. Londrina: UEL, 1999. p. 11-17.

KEMMIS, S. Critical reflection. Deakin University, Geelong, Austrália (Manuscrito não publicado) apud BARTLETT, L. Teacher development through reflective teaching. In: 
RICHARDS, J. C. \& NUNAN, D. (Ed.) Second language teacher education. New York: Cambridge University Press, 1990.

LANTOLF, J. P. \& APPEL, G. Theoretical framework: an introduction to Vygotskian approaches to second language research. In: LANTOLF, J. P. \& APPEL, G. (eds.). Vygotskian Approaches to Second Language Research. Norwood, NJ: Ablex Publishing Corporation, 1994.

MATTOS, A. M. A. Percepções de uma professora de inglês sobre sua sala de aula: uma visão êmica. 2000. 149 f. Dissertação (Mestrado em Lingüística Aplicada ao Ensino de Línguas Estrangeiras) - Faculdade de Letras, Universidade Federal de Minas Gerais, Belo Horizonte.

MOITA LOPES, L. P. Oficina de Língüistica Aplicada. Campinas: Mercado das Letras, 1996.

ORTENZI, D. I. B. G. Da prescrição à autonomia. In: GIMENEZ, T. (Org.). Os sentidos do projeto NAP: ensino de línguas e formação continuada do professor. Londrina: UEL, 1999.

PICA, T. A. relação professor/pesquisador: múltiplas perspectivas e possibilidades. Linguagem \& Ensino, 3(1): 55-88, 2000. p. 41-5.

REIS, S. Os sentidos de uma proposta de ação e reflexão no ensino de língua inglesa em escolas públicas. In: GIMENEZ, T. (Org.). Os sentidos do projeto NAP: ensino de línguas e formação continuada do professor. Londrina: UEL, 1999. p. 33-40.

REGO, T.C. Vygotsky: uma perspectiva histórico-cultural da educação. Petrópolis: Vozes, 1994.

RICHARDS, J. C. Beyond training. New York: Cambridge University Press, 1998.

RICHARDS, J. C. \& LOCKHART, C. Reflective teaching in second language classrooms. New York: Cambridge University Press, 1994.

RICHARDS, J. C. \& NUNAN, D. (Ed.) Second language teacher education. New York: Cambridge University Press, 1990.

RUDDOCK, J. Teaching as an art, teacher research and research-based teacher education. Second Annual Lawrence Stenhouse Memorial Lecture, University of East Anglia, 1984 apud WILLIAMS, M. \& BURDEN, R. L. Psychology for language teachers: a social constructivist approach. Cambridge: Cambridge University Press, 1997.

SCHÖN, D. A. The reflective practitioner: how professionals think in action. Cambridge, Mass: Basic Books, 1983.

WALLACE, M. J. Training foreign language teachers: a reflective approach. Glasgow: Cambridge University Press, 1991.

ZEICHNER, K. M. \& LISTON, D. P. Reflective teaching: an introduction. Mahwah, NJ: Lawrence Erlbaum, 1996.

\section{NOTAS:}

\footnotetext{
${ }^{1}$ Os dados desta pesquisa foram coletados em Mattos (2000).

${ }^{2}$ Tradução minha, assim como todas as outras citações feitas a partir de autores estrangeiros, no restante deste trabalho.

${ }^{3}$ Segundo Zeichner \& Liston (1996:14-5), Schön sugere que prática reflexiva inclui os conceitos de "reflexão sobre a ação", ou seja, aquela que ocorre antes ou depois de uma ação, e "reflexão na ação", aquela que ocorre durante uma ação, na tentativa de solucionar problemas no momento em que são encontrados. É também Schön quem ressalta a importância do conhecimento que o professor tem de sua prática, o que ele chamou de "conhecimento na ação".
} 


\footnotetext{
${ }^{4} \mathrm{O}$ uso das duas terminologias se deve ao fato de que o próprio autor faz uso de ambos os termos no seu modelo: o estágio 1 é chamado de pré-treinamento, e o estágio 2 de desenvolvimento profissional. Essa contradição provavelmente acontece porque o modelo foi proposto em uma época de transição entre a situação vigente em que predominava o treinamento e as novas sugestões para o desenvolvimento do professor.

${ }^{5}$ O NAP (Núcleo de Assessoria Pedagógica para Ensino de Línguas) é um projeto da Faculdade de Letras da Universidade Estadual de Londrina, que tem por objetivo capacitar e assessorar professores de línguas do ensino fundamental e médio.

${ }^{6}$ Tradução minha do termo original "more capable peer".

${ }^{7}$ O CENEX oferece cursos de línguas estrangeiras para alunos, professores e funcionários da UFMG e para a comunidade em geral. Os professores desses cursos são, preferencialmente, os alunos dos cursos de letras da FALE (Faculdade de Letras), que ali cumprem seu estágio curricular.

${ }^{8}$ Por questões de espaço, a ampliação da relação de categorias reflexivas de Richards (1998) não será discutida neste trabalho.

${ }^{9}$ Convenções Adotadas nas Transcrições:

$\mathrm{I} \rightarrow$ Informante

$\mathrm{P} \rightarrow$ Pesquisadora

$\ldots \rightarrow$ Pausa breve ou hesitação

[pausa] $\rightarrow$ Pausa longa

[ ] $\rightarrow$ Comentários da pesquisadora, inseridos durante a transcrição dos dados ou durante a seleção e apresentação dos exemplos para facilitar a compreensão

$(\ldots) \rightarrow$ Comentários não relevantes para o ponto em questão

$\mathrm{J}, \mathrm{MF}, \mathrm{ML}, \mathrm{V} \rightarrow$ Alunas do curso, cujo nome foi apagado para preservar seu anonimato
}

\section{ANEXO I \\ Relação Expandida de Categorias Reflexivas}

\section{I - Teorias de Ensino}

\section{1 - Teorias e crenças sobre ensino e aprendizagem}

- uma crença ou convicção (ex: o que é ser um bom professor)

- a visão de um especialista (ex: referir-se às idéias de seus professores na universidade)

- uma justificativa para algo (ex: descrever uma teoria ou crença para justificar algo que o professor fez)

- uma opinião pessoal (ex: expressar uma opinião sobre a importância da observação de aula)

2 - Aplicação de teorias à prática de sala de aula

- como uma teoria foi aplicada (ex: experimentar uma estratégia de elicitação descrita numa palestra)

- contradições entre teoria e prática (ex: descrever porque um evento de sala de aula não sustenta uma teoria)

- como as teorias mudaram (ex: como as experiências de sala de aula mudaram as teorias do professor)

II - Abordagens e Métodos 


\section{1 - Abordagens e métodos de ensino}

- uma abordagem ou um procedimento (ex: a abordagem do professor para o ensino de leitura ou os procedimentos usados durante uma tarefa de compreensão oral)

- justificativas para o uso de uma abordagem ou procedimento (ex: explicar porque usou determinado procedimento para apresentação ou prática de um conteúdo)

\section{2 - Conteúdos de ensino}

- o conteúdo de uma lição ou atividade (ex: descrição do conteúdo de uma lição de gramática)

- o material didático (ex: comentários sobre um exercício proposto pelo livro didático)

3 - O conhecimento do professor

- conhecimento pedagógico (ex: conhecimento sobre as exigências das tarefas de classe)

- conhecimento e experiência (ex: mencionar como sua maneira de ensinar mudou)

4 - O aluno

- as informações prévias do aluno (ex: mencionar que os alunos têm pouca oportunidade de praticar inglês fora da sala de aula)

- percepções sobre o aluno (ex: mencionar que um aluno é tímido ou extrovertido)

5 - O contexto

- a relação entre ensino e contexto (ex: como os níveis anteriores afetam o ensino)

- as pressões à sala de aula (ex: mencionar fatores que influenciam a sala de aula)

III - Avaliações do Ensino

1 - Avaliação de aulas

- avaliações positivas (ex: comentar que a aula foi bem porque todos os alunos participaram)

- avaliações negativas (ex: mencionar que a aula não atingiu seus objetivos)

2 - Diagnóstico de problemas

- problemas dos alunos (ex: dificuldades que os alunos tiveram com determinados pontos gramaticais)

- interação de sala de aula (ex: comentar que uma atividade de grupo não funcionou porque os alunos tiveram problemas de interação em grupo)

- problemas do professor (ex: o professor não teve tempo para preparar uma tarefa extra)

\section{3 - Solução de problemas}

- formas alternativas de apresentar uma lição (ex: começar uma lição de forma diferente)

- decisão de adotar um plano de ação (ex: decidir usar "pair work" com mais freqüência)

- formas de buscar ajuda (ex: pedir ajuda a professores e colegas ou buscar ajuda em dicionários e gramáticas)

IV - Auto-percepção

1 - Percepções de si mesmo como professor

- seu estilo de ensinar (ex: descrever o estilo de ensinar com o qual ele mais se identifica)

- seu estilo de aprender (ex: comentar sobre sua maneira preferencial de aprender)

- comentários sobre sua proficiência na língua (ex: dizer que não fala inglês fluentemente)

2 - Reconhecimento de crescimento pessoal

- como a pesquisa ajudou (ex: mencionar que o uso do vídeo ajuda a perceber problemas)

3 - Estabelecer objetivos pessoais

- auto-desenvolvimento (ex: identificar aspectos de sua maneira de ensinar que devem ser trabalhados)

- planos para o futuro (ex: mencionar que deseja melhorar seu comando da língua estrangeira) 


\section{Questionário de Avaliação}

1- Como você avalia a experiência de refletir sobre as suas aulas? Você acha que foi útil ou não? Por quê?

2- O que você considerou positivo ou negativo sobre esta experiência?

3- Você já tinha feito algo parecido antes? (se afirmativo, por favor comente)

4- O que você acha que aprendeu a partir desta experiência?

5- Você acredita que refletir sobre suas aulas teve um efeito positivo sobre a sua maneira de ensinar? Qual?

6- Você acredita que refletir sobre suas aulas teve um efeito positivo sobre o seu processo de aprender a ensinar? Qual?

7- Compare você hoje com você mesma antes de participar desta pesquisa. Você vê alguma mudança? Qual?

8- O que você não conseguiu mudar?

9- Em termos de seu comportamento como professora de língua estrangeira, o que você acha que vai passar a fazer em suas aulas em decorrência da auto-observação? O que você acha que vai continuar a fazer? O que você acha que vai parar de fazer?

10- Você acredita que seu desempenho futuro como professora será diferente devido à sua participação nesta pesquisa? Por quê?

11- Você acredita que seus alunos foram beneficiados porque você participou desta pesquisa? Como?

12- Você acredita que uma experiência como esta seria positiva para outros professores? Por quê?

13-O que você modificaria ou acrescentaria para melhorar o uso da reflexão como instrumento de auto-desenvolvimento do professor de língua estrangeira?

14- Faça outros comentários que desejar: 